\title{
Empirical Modeling of the Government and Corporate Bond Yields: The Case of Japan
}

\author{
Chikashi Tsuji \\ Professor, Faculty of Economics, Chuo University \\ 742-1 Higashinakano Hachioji-shi, Tokyo 192-0393, Japan \\ E-mail: mail_sec_low@minos.ocn.ne.jp
}

Received: February 19, 2015 Accepted: March 3, 2015 Published: April 1, 2015

doi:10.5296/jmr.v7i3.7127 URL: http://dx.doi.org/10.5296/jmr.v7i3.7127

\begin{abstract}
This paper takes an empirical approach to modeling the relations among various Japanese bond yields by applying the vector error correction models (VECMs). Our empirical examinations derive several interesting findings as follows. First, we reveal that 1) the bivariate relations of various Japanese bond yields are effectively captured by the cointegrating equations (CEs) in the VECMs and 2) the CEs often well explain the one-month-ahead changes of the various Japanese bond yields. Further, our impulse response analyses also clarify that 3) the yields of the Nikkei bond indices are mutually positively related and 4) the Japanese government bond (JGB) yields are much strongly affected by the corporate bond yields in Japan.
\end{abstract}

Keywords: Corporate bond yield, Cointegration, JGB, Term structure, VECM 


\section{Introduction}

Analyzing the time-series relations and their dynamic changes of the multiple bond yields is appealing research topic since the term structure of various bond yields includes rich information not only of the bond markets but also the macroeconomy. Many existing literature attempted to model and analyze interest rates and their term structure (See for example, Vasicek, 1977; Cox et al., 1985; Hull and White, 1990; Heath et al., 1992). The time-series dynamic evolution of the term structure of interest rates generally shifts in accordance with the changes of the economic environment, and thus it is difficult to explain the dynamic linkage by one theory. Therefore, it is considered that the empirical approach shall be very natural and useful for modeling the term structure.

Based on the above motivation, this paper attempts to empirically model the term structure of several Japanese bond yields. Specifically, we employ the bivariate-vector error correction models (VECMs) and aim to capture the dynamic linkage among four kinds of bond yields in Japan. The interesting findings from our study are as follows. First, we reveal that 1) the bivariate relations among various Japanese bond yields are effectively captured by the cointegrating equations (CEs) in the VECMs and 2) the CEs often well explain the next month's changes of various Japanese bond yields. Further, our impulse response analyses also find that 3) the yields of the Nikkei bond indices are mutually positively related and 4) the Japanese government bond (JGB) yields are much strongly affected by the corporate bond yields in Japan. After this introduction, Section 2 reviews the related literature; Section 3 explains our data and variables; Sections 4 describes our models; Section 5 documents our results; Section 6 summarizes the paper.

\section{Literature review}

This section concisely reviews very recent existing related studies. Filipova et al. (2014) developed a multivariate dynamic term structure model, which considered the nonlinear linkage between the state of the economy and interest rates. Chen et al. (2014) evidenced that investor sentiment and the peso problem were very important in explaining expectation errors, and they also suggested that their results rejected the unbiased expectation hypothesis. Juneja (2014) evaluated the effects of autocorrelation on parameter estimates of affine term structure models (ATSMs) when factors are extracted by using the principal component analysis.

Further, Shaw et al. (2014) extended and applied the dynamic Nelson-Siegel model (Nelson and Siegel, 1987) developed by Diebold and Li (2006) to credit default swaps (CDSs). Their results indicated that the CDS curve fitted the data well and successfully captured the various shapes of the CDS data, such as steep, inverted, and downward sloping curves of the CDS. Brooks et al. (2015) examined the information contained in the term structures of the London Interbank Offered Rate (LIBOR) and the US Constant Maturity Treasury. Their main finding was that the information embedded in the two term structures was significantly different. Creal and $\mathrm{Wu}$ (2015) developed new procedures of maximum likelihood estimation of ATSMs with spanned or unspanned stochastic volatility. They found that spanned stochastic volatility models effectively explained the cross-section of yields whilst unspanned stochastic volatility models well captured the volatility. 
Table 1. Descriptive statistics of the Japanese bond yields

\begin{tabular}{lll}
\hline & CS & CM \\
\hline Mean & 3.2002 & 3.4240 \\
Median & 1.9300 & 2.3450 \\
Maximum & 11.4700 & 10.0000 \\
Minimum & 0.2300 & 0.2000 \\
Std. Dev. & 2.7726 & 2.7060 \\
Skewness & 0.7620 & 0.5873 \\
Kurtosis & 2.3242 & 1.9535 \\
\hline & CL & JGB \\
\hline Mean & 3.8630 & 3.5666 \\
Median & 2.8150 & 2.4585 \\
Maximum & 9.6900 & 8.8880 \\
Minimum & 0.6400 & 0.4390 \\
Std. Dev. & 2.5281 & 2.5740 \\
Skewness & 0.5313 & 0.5584 \\
Kurtosis & 1.8612 & 1.8548 \\
\hline
\end{tabular}

Notes: This table shows the descriptive statistics with regard to the variables we investigate in this study. In this table, 'Std. Dev.' means the standard deviation value. Moreover, CS denotes the short-term Nikkei bond index yield; CM means the middle-term Nikkei bond index yield; CL denotes the long-term Nikkei bond index yield; JGB means the 10-year Japanese government bond yield. Our sample period spans January 1980 to December 2014, and the number of the observations analyzed is 420 .

\section{Data}

In this section, we describe the data used in this study. This study uses four kinds of Japanese bond yields. Specifically, CS denotes the short-term Nikkei bond index yield; CM means the middle-term Nikkei bond index yield; CL denotes the long-term Nikkei bond index yield; JGB means the 10-year Japanese government bond yield. We note that the Nikkei bond indices include the public and corporate bonds in Japan, thus CS, CM, and CL reflect the credit risk in the Japanese bond markets. Further, our sample period is from January 1980 to December 2014 and all data used in this study are from the QUICK Corp.

The time-series trends of the above four kinds of Japanese bond yields are shown in Figure 1 and their descriptive statistics are exhibited in Table 1. As Figure 1 shows, around 1990, JGB and the other bond yields once rose due to the bubble economy in Japan, and then they continuously decreased until the recent years. In addition, from Table 1, we understand the following data characteristics. First, 1) as their maturities are longer, the mean values of the Nikkei bond index yields become higher. Second, 2) the mean value of the JGB yield is higher than those of short-term and middle-term Nikkei bond index yields. Third, 3) volatility of the variable CS is the highest and that of the variable CL is the lowest in four variables. 


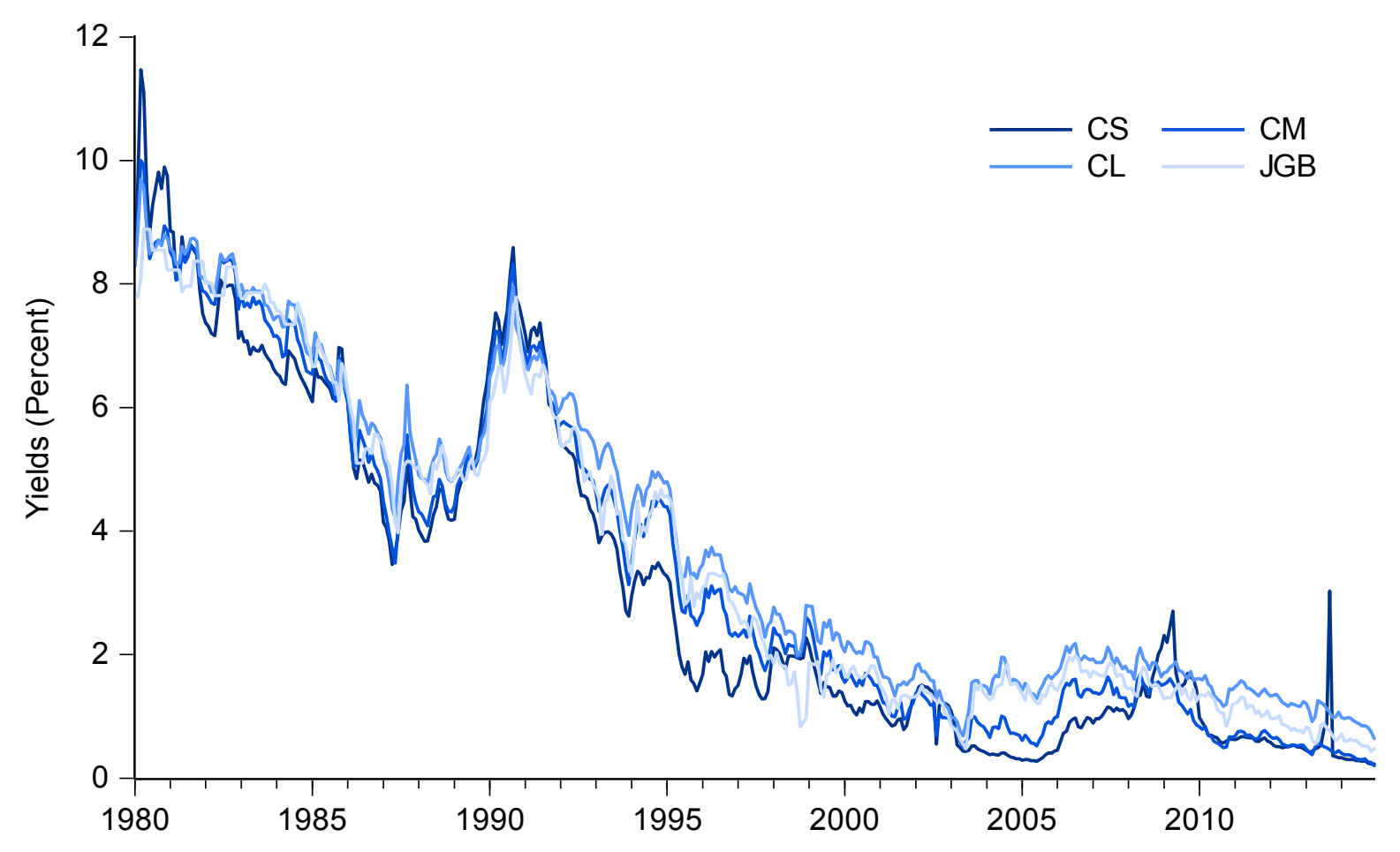

Figure 1. Time-series Evolution of the Japanese Bond Yields: For the Period from January 1980 to December 2014.

\section{Empirical models}

This section documents our empirical models. In order to model the term structure of the JGB and the other Japanese bond yields under the period from January 1980 to December 2014, this study estimates six kinds of VECMs. Namely, the models we investigate in this research are the bivariate-VECMs of 1) CM and CS; 2) CL and CS; 3) CL and CM; 4) CS and JGB; 5) CM and JGB; 6) CL and JGB. Our model determinations are based on the Johansen's (1991; 1995) cointegration tests and we can summarize all our models as the following equations (1) and (2).

$$
\begin{aligned}
& \Delta y_{t}=\tau_{1} C E+\sum_{h=1}^{p} \xi_{1, h} \Delta y_{t-h}+\sum_{j=1}^{q} \phi_{1, j} \Delta z_{t-j}+\kappa_{1, t}, \\
& \Delta z_{t}=\tau_{2} C E+\sum_{r=1}^{p} \xi_{2, r} \Delta y_{t-r}+\sum_{s=1}^{q} \phi_{2, s} \Delta z_{t-s}+\kappa_{2, t} .
\end{aligned}
$$

In the above models, all CEs include an intercept as $C E=y_{t-1}+\lambda z_{\mathrm{t}-1}+\eta$ whilst two equations (1) and (2) have no intercept. In addition, the lag orders $p$ and $q$ in our VECMs are different according to models. Namely, our determined six models for the Japanese bond yields are 1) $\operatorname{VECM}(1,1)$ for $\mathrm{CM}$ and $\mathrm{CS} ; 2) \operatorname{VECM}(9,9)$ for CL and CS; 3) $\operatorname{VECM}(4,4)$ for CL and CM; 4) $\operatorname{VECM}(1,1)$ for CS and JGB; 5) $\operatorname{VECM}(1,1)$ for $\mathrm{CM}$ and JGB; 6) $\operatorname{VECM}(1,1)$ for CL and JGB. Further, in the above equations, $y$ and $z$ are two variables that are included in the bivariate-VECMs. Moreover, $\Delta y$ and $\Delta z$ denote the first differences of the variables $y$ and $z$, respectively. 
Table 2. Estimation results of the VECMs for the Japanese bond yields

\begin{tabular}{|c|c|c|c|c|c|}
\hline \multicolumn{3}{|c|}{ Panel A. CM and CS } & \multicolumn{3}{|c|}{ Panel B. CL and CS } \\
\hline \multicolumn{3}{|c|}{ Cointegrating equation } & \multicolumn{3}{|c|}{ Cointegrating equation } \\
\hline & \multicolumn{2}{|l|}{ Coefficients } & & \multicolumn{2}{|l|}{ Coefficients } \\
\hline $\mathrm{CM}(-1)$ & \multicolumn{2}{|l|}{1.0000} & $\mathrm{CL}(-1)$ & \multicolumn{2}{|l|}{1.0000} \\
\hline $\mathrm{CS}(-1)$ & \multicolumn{2}{|l|}{$-1.0172 * * *$} & $\operatorname{CS}(-1)$ & \multicolumn{2}{|l|}{$-0.9663 * * *$} \\
\hline$p$-value & \multicolumn{2}{|l|}{0.0000} & $p$-value & \multicolumn{2}{|l|}{0.0000} \\
\hline Intercept & \multicolumn{2}{|l|}{-0.1679} & Intercept & \multicolumn{2}{|l|}{$-0.6384 * * *$} \\
\hline$p$-value & \multicolumn{2}{|l|}{0.3065} & $p$-value & \multicolumn{2}{|l|}{0.0002} \\
\hline \multicolumn{3}{|c|}{ Error corrections } & \multicolumn{3}{|c|}{ Error corrections } \\
\hline & \multicolumn{3}{|l|}{ Variables } & \multicolumn{2}{|l|}{ Variables } \\
\hline & $\Delta \mathrm{CM}$ & $\Delta \mathrm{CS}$ & & $\Delta \mathrm{CL}$ & $\Delta \mathrm{CS}$ \\
\hline & Coefficients & Coefficients & & Coefficients & Coefficients \\
\hline $\mathrm{CE}$ & 0.0005 & $0.0906^{* * *}$ & $\mathrm{CE}$ & $-0.0398 * *$ & $0.0517 *$ \\
\hline$p$-value & 0.9832 & 0.0050 & $p$-value & 0.0291 & 0.0509 \\
\hline$\Delta \mathrm{CM}(-1)$ & $0.1736 * *$ & $0.4964 * * *$ & $\Delta \mathrm{CL}(-1)$ & 0.1018 & $0.3950 * * *$ \\
\hline$p$-value & 0.0115 & 0.0000 & $p$-value & 0.1042 & 0.0000 \\
\hline$\Delta \mathrm{CS}(-1)$ & 0.0619 & $-0.1853 * * *$ & $\Delta \mathrm{CL}(-2)$ & -0.0271 & 0.0374 \\
\hline \multirow[t]{19}{*}{$p$-value } & \multirow[t]{19}{*}{0.2064} & \multirow[t]{19}{*}{0.0069} & $p$-value & 0.6724 & 0.6886 \\
\hline & & & $\Delta \mathrm{CL}(-3)$ & $-0.1085^{*}$ & -0.0683 \\
\hline & & & $p$-value & 0.0912 & 0.4642 \\
\hline & & & $\Delta \mathrm{CL}(-4)$ & $-0.1317 * *$ & 0.0145 \\
\hline & & & $p$-value & 0.0413 & 0.8764 \\
\hline & & & $\Delta \mathrm{CL}(-5)$ & -0.0121 & 0.0282 \\
\hline & & & $p$-value & 0.8524 & 0.7654 \\
\hline & & & $\Delta \mathrm{CL}(-6)$ & -0.0086 & -0.0846 \\
\hline & & & $p$-value & 0.8937 & 0.3649 \\
\hline & & & $\Delta \mathrm{CL}(-7)$ & -0.0110 & -0.0003 \\
\hline & & & $p$-value & 0.8637 & 0.9970 \\
\hline & & & $\Delta \mathrm{CL}(-8)$ & -0.0262 & -0.0034 \\
\hline & & & $p$-value & 0.6810 & 0.9710 \\
\hline & & & $\Delta \mathrm{CL}(-9)$ & -0.0107 & 0.0376 \\
\hline & & & $p$-value & 0.8637 & 0.6779 \\
\hline & & & $\Delta \mathrm{CS}(-1)$ & 0.0225 & $-0.2089 * * *$ \\
\hline & & & $p$-value & 0.6057 & 0.0011 \\
\hline & & & $\Delta \mathrm{CS}(-2)$ & 0.0476 & 0.0247 \\
\hline & & & $p$-value & 0.2866 & 0.7038 \\
\hline
\end{tabular}




\begin{tabular}{|c|c|c|c|c|c|}
\hline & & & $\Delta \mathrm{CS}(-3)$ & 0.0489 & 0.0536 \\
\hline & & & $p$-value & 0.2739 & 0.4094 \\
\hline & & & $\Delta \mathrm{CS}(-4)$ & -0.0163 & -0.0637 \\
\hline & & & $p$-value & 0.7139 & 0.3257 \\
\hline & & & $\Delta \mathrm{CS}(-5)$ & -0.0514 & -0.0217 \\
\hline & & & $p$-value & 0.2476 & 0.7370 \\
\hline & & & $\Delta \mathrm{CS}(-6)$ & -0.0106 & 0.0248 \\
\hline & & & $p$-value & 0.8057 & 0.6933 \\
\hline & & & $\Delta \mathrm{CS}(-7)$ & 0.0069 & 0.0570 \\
\hline & & & $p$-value & 0.8725 & 0.3592 \\
\hline & & & $\Delta \mathrm{CS}(-8)$ & 0.0326 & $0.1068^{*}$ \\
\hline & & & $p$-value & 0.4308 & 0.0763 \\
\hline & & & $\Delta \mathrm{CS}(-9)$ & 0.0169 & $0.0964 *$ \\
\hline & & & $p$-value & 0.6709 & 0.0953 \\
\hline Adj. $R^{2}$ & 0.0479 & 0.0791 & $\operatorname{Adj.} R^{2}$ & 0.0282 & 0.0557 \\
\hline Panel C. C & $\mathrm{d} C M$ & & Panel D. C & d JGB & \\
\hline Cointegrat & equation & & Cointegrati & quation & \\
\hline & Coefficients & & & Coefficients & \\
\hline $\mathrm{CL}(-1)$ & 1.0000 & & $\mathrm{CS}(-1)$ & 1.0000 & \\
\hline $\mathrm{CM}(-1)$ & $-0.9313 * * *$ & & $\operatorname{JGB}(-1)$ & $-1.0462 * * *$ & \\
\hline$p$-value & 0.0000 & & $p$-value & 0.0000 & \\
\hline Intercept & $-0.5970 * * *$ & & Intercept & $0.4786^{* *}$ & \\
\hline$p$-value & 0.0000 & & $p$-value & 0.0187 & \\
\hline Error corre & & & Error corre & & \\
\hline & Variables & & & Variables & \\
\hline & $\Delta \mathrm{CL}$ & $\Delta \mathrm{CM}$ & & $\Delta \mathrm{CS}$ & $\triangle \mathrm{JGB}$ \\
\hline & Coefficients & Coefficients & & Coefficients & Coefficients \\
\hline $\mathrm{CE}$ & $-0.1087 * *$ & -0.0597 & $\mathrm{CE}$ & $-0.0479 * *$ & $0.0644 * * *$ \\
\hline$p$-value & 0.0122 & 0.2014 & $p$-value & 0.0396 & 0.0000 \\
\hline$\Delta \mathrm{CL}(-1)$ & 0.0295 & 0.0444 & $\Delta \mathrm{CS}(-1)$ & 0.0790 & $0.2313 * * *$ \\
\hline$p$-value & 0.8330 & 0.7691 & $p$-value & 0.1230 & 0.0000 \\
\hline$\Delta \mathrm{CL}(-2)$ & -0.1222 & -0.1475 & $\Delta \mathrm{JGB}(-1)$ & -0.0365 & 0.0562 \\
\hline$p$-value & 0.3831 & 0.3301 & $p$-value & 0.6098 & 0.1992 \\
\hline$\Delta \mathrm{CL}(-3)$ & -0.1057 & -0.1817 & & & \\
\hline$p$-value & 0.4479 & 0.2280 & & & \\
\hline$\Delta \mathrm{CL}(-4)$ & 0.0221 & 0.0161 & & & \\
\hline$p$-value & 0.8730 & 0.9144 & & & \\
\hline
\end{tabular}




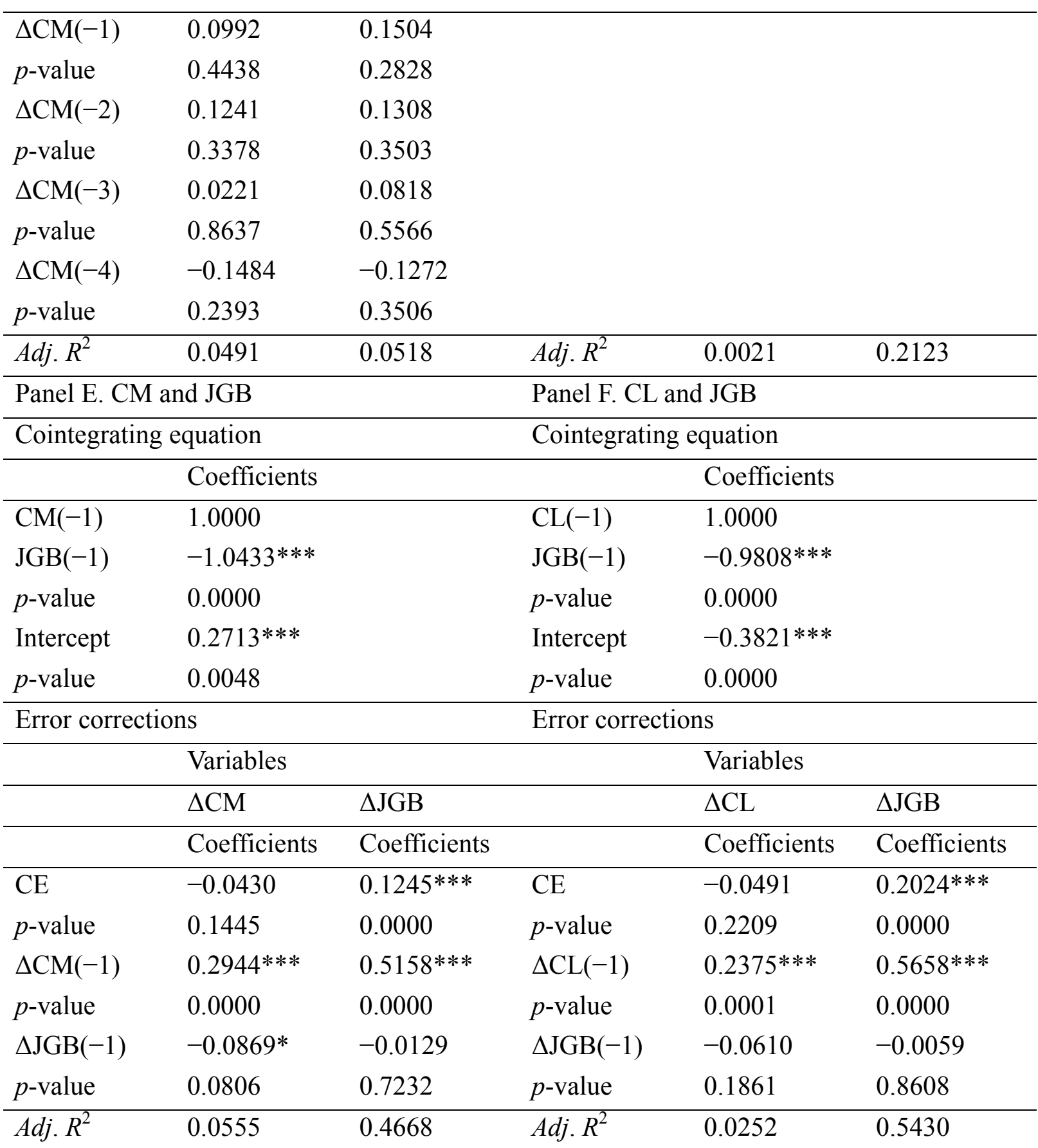

Notes: This table demonstrates the results of estimation as to the bivariate-VECMs for four kinds of Japanese bond yields. In this table, CS denotes the short-term Nikkei bond index yield; CM means the middle-term Nikkei bond index yield; CL denotes the long-term Nikkei bond index yield; JGB means the 10-year Japanese government bond yield. Panel A of this table shows the results of CM and CS, Panel B exhibits the results of CL and CS, Panel C displays the results of CL and CM, Panel D shows the results of CS and JGB, Panel E exhibits the results of CM and JGB, and Panel F shows the results of CL and JGB. Samples are monthly and our full sample period spans January 1980 to December 2014. Further, the number of our observations is 420 . Moreover, CE means the cointegrating equation and Adj. $R^{2}$ denotes the adjusted $R$-squared value. Furthermore, $* * *, * *$, and $*$ denote the statistical significance at the 1,5 , and $10 \%$ levels, respectively. 
Panel A. CM and CS

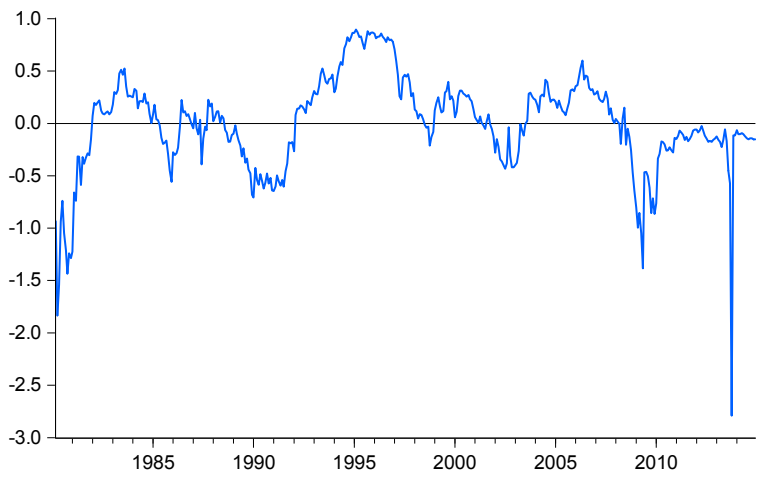

Panel C. CL and CM

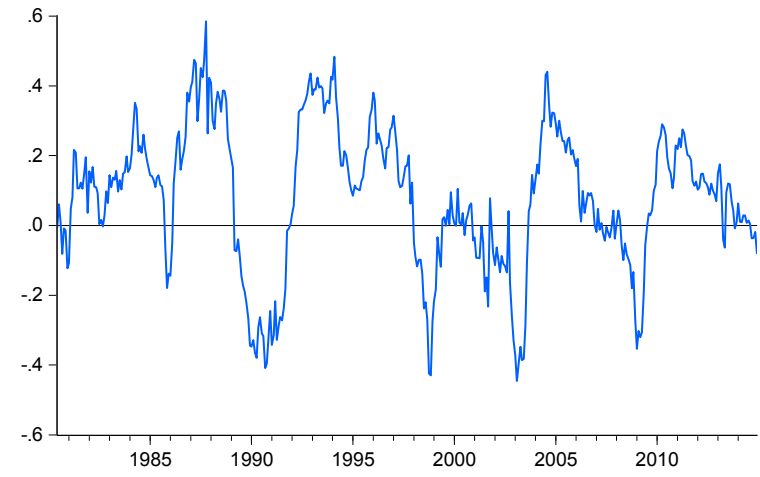

Panel E. CM and JGB

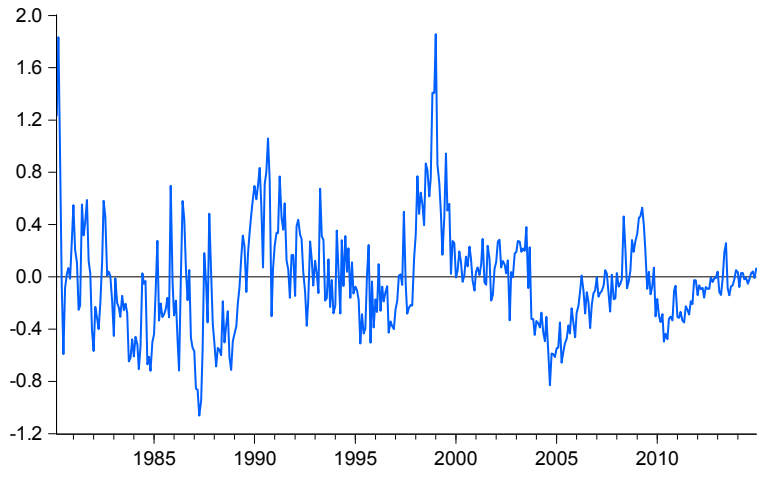

Panel B. CL and CS

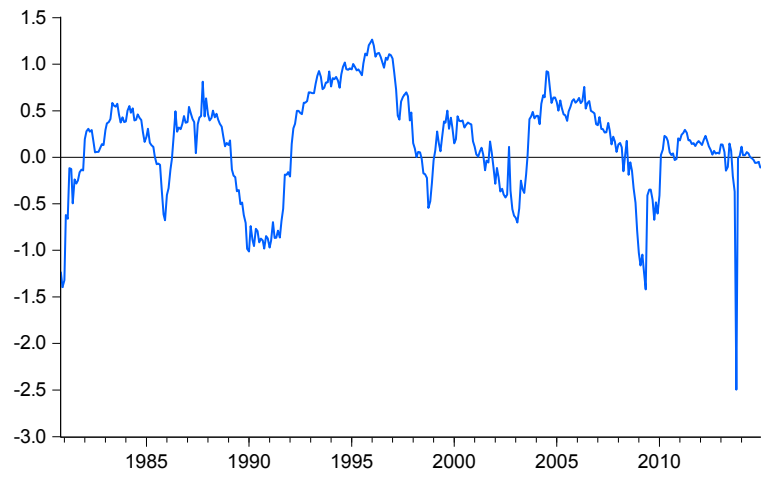

Panel D. CS and JGB

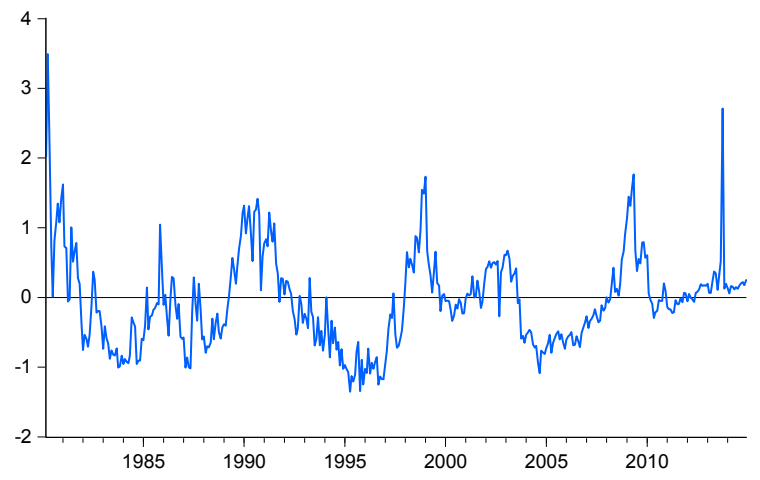

Panel F. CL and JGB

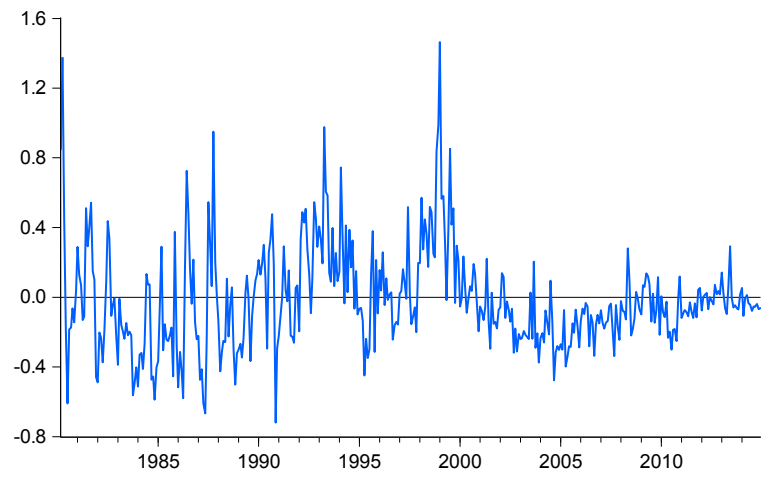

Figure 2. Time-series Evolution of the Cointegrating Equations Derived from the VECMs.

\section{Empirical results}

Estimation results of our six kinds of VECMs are shown in Table 2. More specifically, in Table 2, Panel A shows the results of CM and CS, Panel B exhibits the results of CL and CS, Panel C displays those of CL and CM, Panel D shows those of CS and JGB, Panel E exhibits those of CM and JGB, and Panel F shows those of CL and JGB. Moreover, the evolution of the CEs derived from the VECMs is shown in Figure 2. In Figure 2, Panel A shows the time-series of the CE for CM and CS, Panel B exhibits the time-series of the CE for CL and 


\section{Macrothink}

CS, Panel C displays that of the CE for CL and CM, Panel D shows the CE for CS and JGB, Panel E exhibits the CE for CM and JGB, and Panel F shows the CE for CL and JGB. From Table 2, we understand that 1 ) all coefficients $\lambda$ s in the CEs are statistically significant with negative signs in all six models and 2) the coefficients of the CEs in the VECMs are mostly statistically significant. Specifically, in Table 2, the CEs are statistically significant for explaining $\Delta \mathrm{CS}$ (Panel A), $\Delta \mathrm{CL}$ and $\Delta \mathrm{CS}$ (Panel B), $\Delta \mathrm{CL}$ (Panel C), $\Delta \mathrm{CS}$ and $\Delta \mathrm{JGB}$ (Panel D), $\triangle \mathrm{JGB}$ (Panel E), and $\triangle \mathrm{JGB}$ (Panel F). Therefore, it is understood that our VECMs well capture the time-series linkage among the various bond yields in Japan.

In order to interpret the relations among the Japanese different bond yields, we describe the impulse response functions in Figure 3. In this figure, Panel A shows the response of CS to CM, Panel B exhibits that of CM to CS, Panel C displays that of CS to CL, Panel D shows that of CL to CS, Panel E exhibits that of CM to CL, and Panel F shows that of CL to CM. Further, Panel G shows the response of CS to JGB, Panel H exhibits that of JGB to CS, Panel I displays that of CM to JGB, Panel J shows that of JGB to CM, Panel K exhibits that of CL to JGB, and Panel L displays that of JGB to CL. From Figure 3, we understand that 1) the Nikkei bond index yields are mutually positively related (Panels A to F except for Panel E) and 2) the yields of the JGBs are strongly affected by the corporate bond yields in Japan since JGB yields respond to the Nikkei bond index yields much more strongly (Panels G to L).

Panel A. Response of CS to CM

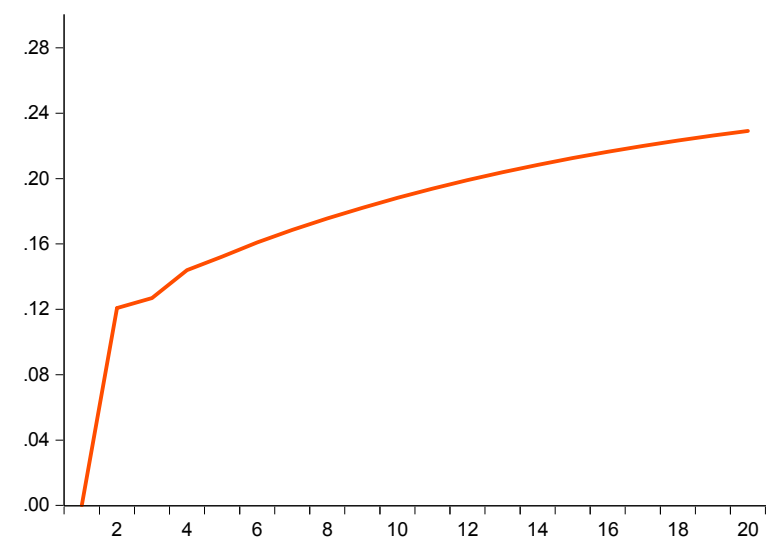

Panel C. Response of CS to CL

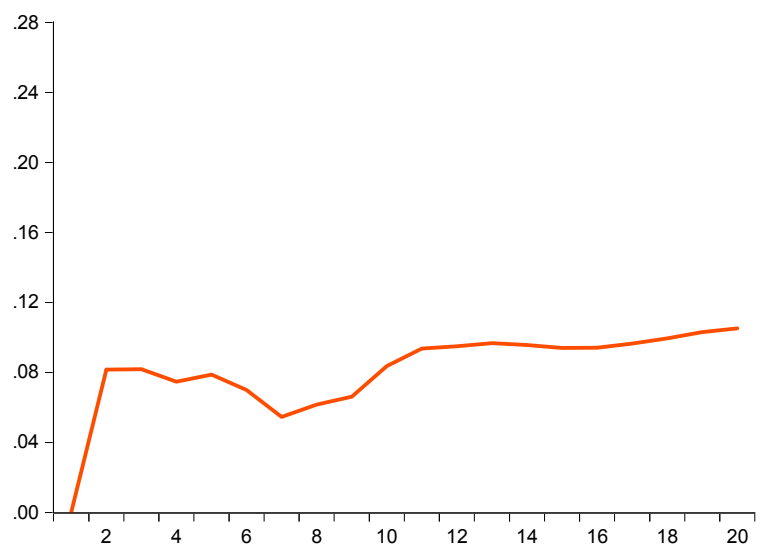

Panel B. Response of CM to CS

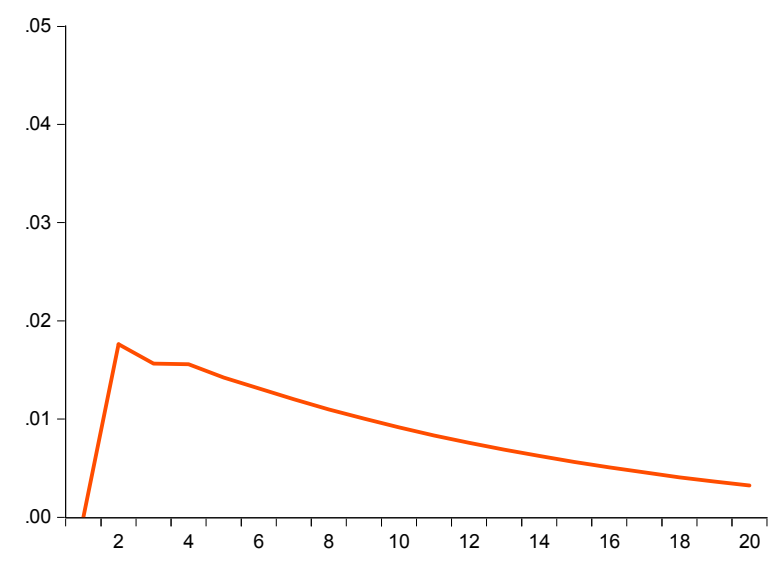

Panel D. Response of CL to CS

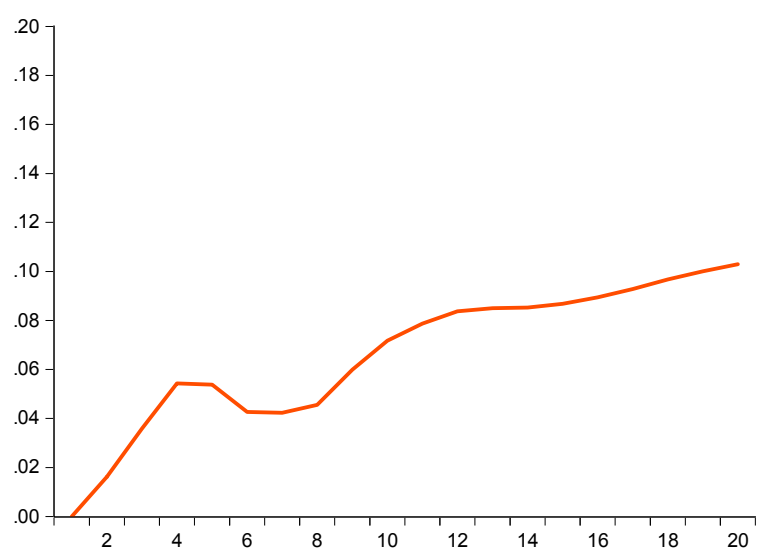


Panel E. Response of CM to CL

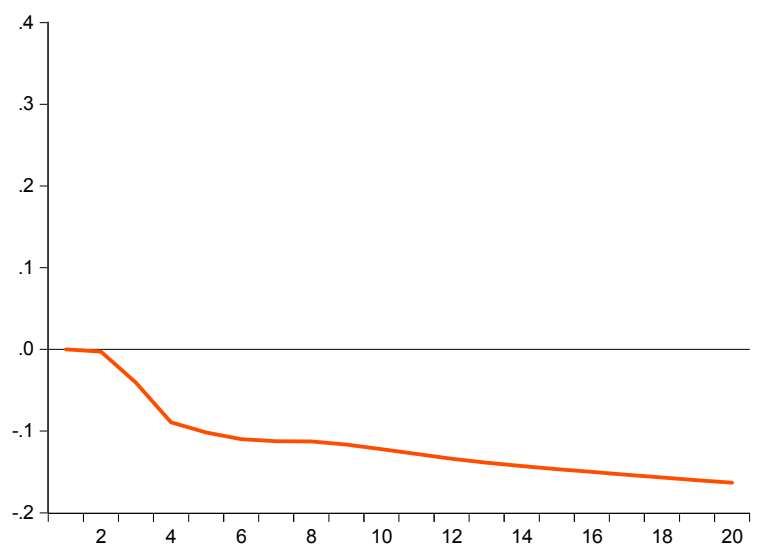

Panel G. Response of CS to JGB

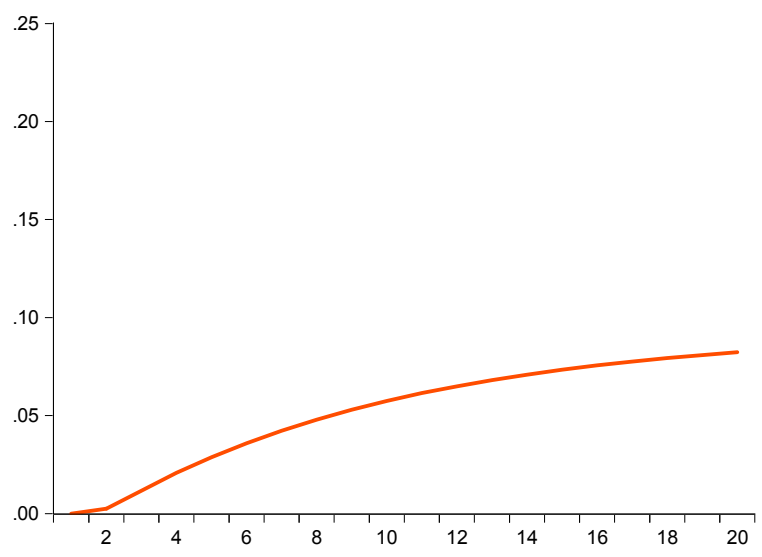

Panel I. Response of CM to JGB

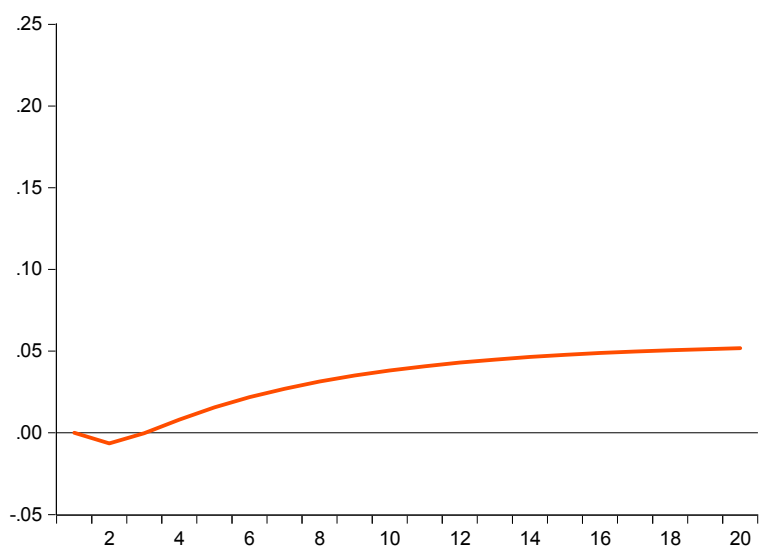

Panel F. Response of CL to CM

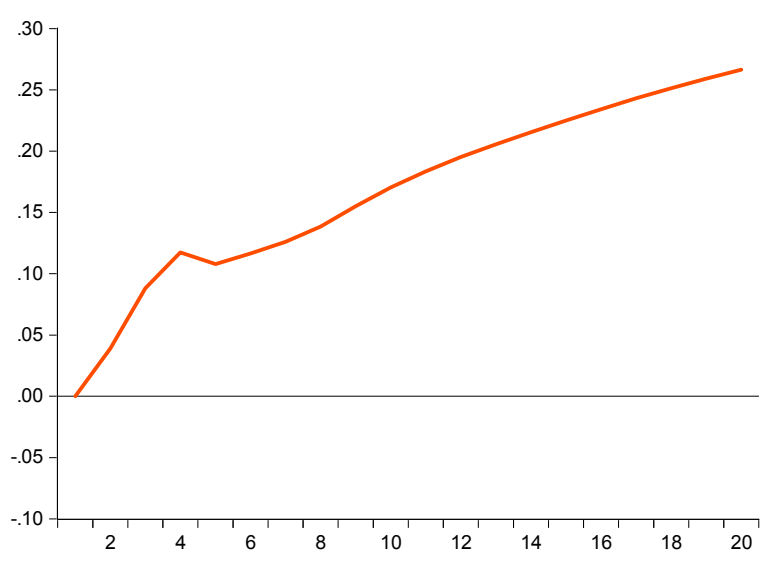

Panel H. Response of JGB to CS

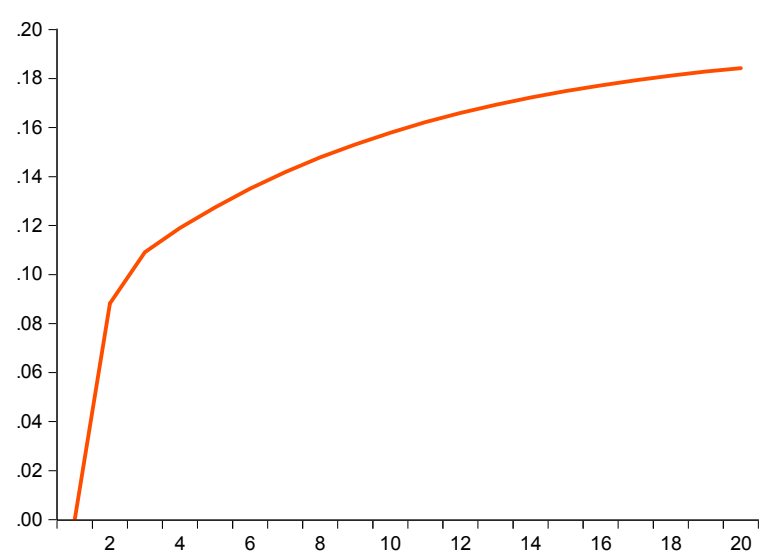

Panel J. Response of JGB to CM

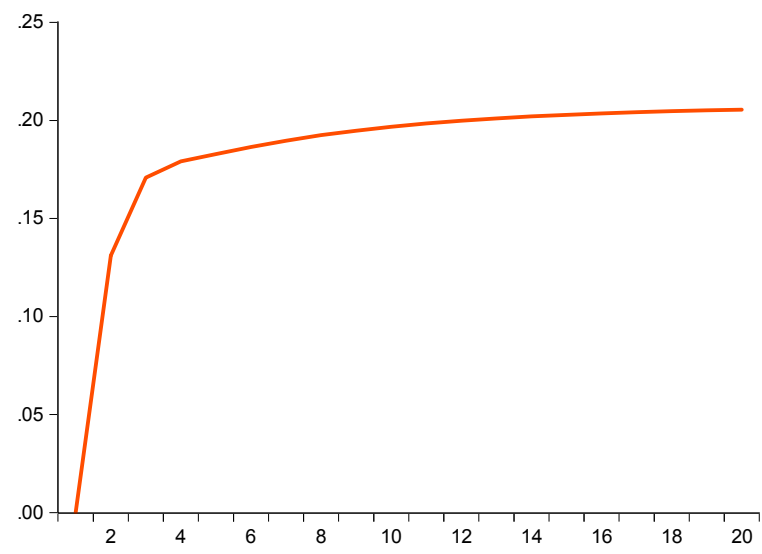


Panel K. Response of CL to JGB

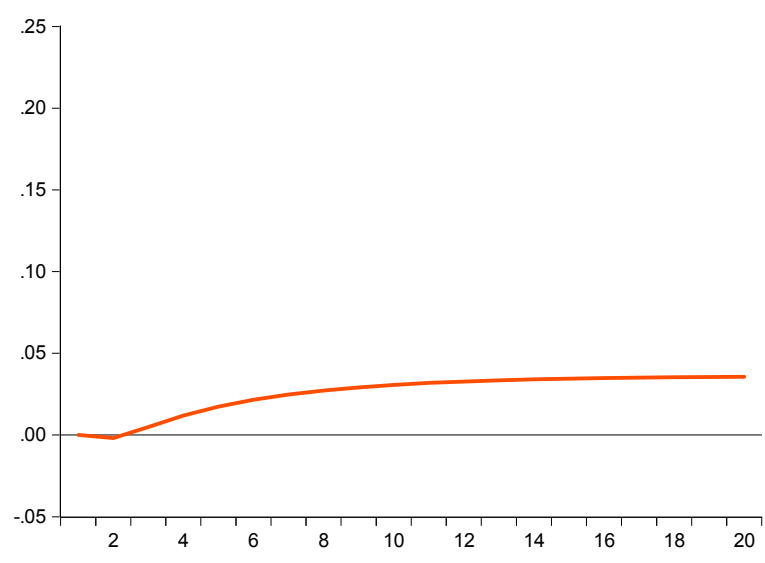

Panel L. Response of JGB to CL

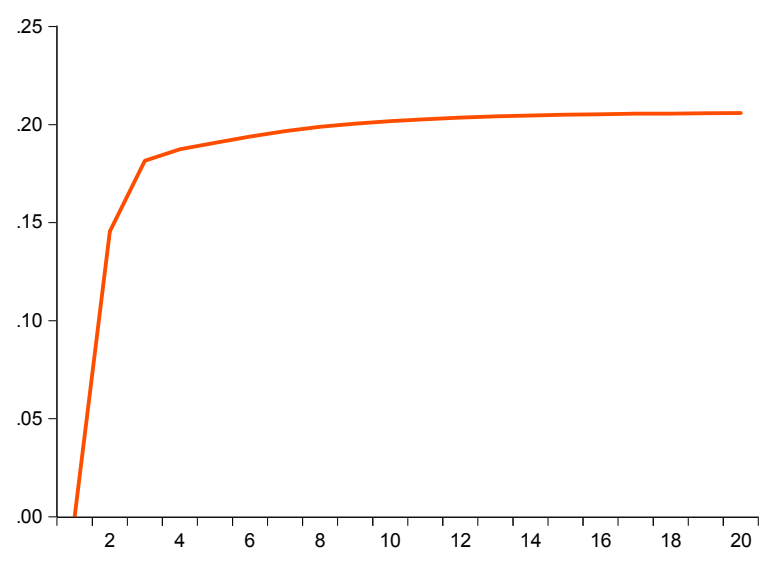

Figure 3. Mutual Impulse Responses of Various Bond Yields in Japan.

\section{Conclusions}

This paper attempted to model the relations among the various Japanese bond yields by applying the VECMs. Our empirical examinations derived several interesting findings as follows. First, we found that 1) the bivariate relations of the various Japanese bond yields were effectively captured by the cointegrating equations in the VECMs and 2) the CEs well explained the one-month-ahead changes of the various Japanese bond yields. Moreover, our impulse response analyses further revealed that 3 ) the yields of the Nikkei bond indices were mutually positively related and 4) the JGB yields were much strongly affected by the corporate bond yields in Japan.

We consider that the findings from our study are informative and useful for the future research. For example, it may be interesting to analyze the linkage among various bond yields of other international countries during financial crises because the state of the economy and financial markets changes during such unstable periods. This kind of analysis by applying VECMs may reveal further empirical findings and it shall be useful to deepen our knowledge and for further understanding of the world economy and international bond markets. Moreover, including high-yield bonds into such analyses may be also interesting. These kinds of studies shall be our future works and we consider that our present study that analyzed the Japanese bond markets by using VECMs should be an important step for many related future researches.

\section{Acknowledgement}

I am particularly grateful to the repeated kind invitation from the journal to write to this journal. I also appreciate the Japan society for the promotion of science, Zengin Foundation for Studies on Economics and Finance, and the Chuo university grant for special research for their generous financial assistance to this research. Moreover, I thank the anonymous referees of this journal for their very quick reviews and kind comments to this paper. Furthermore, I particularly thank the Editor, Lucy Xu, for the kind and quick decision on my paper. Finally, I 
deeply thank the Editors of this journal for their kindness to this paper.

\section{References}

Brooks, R., Cline, B. N., \& Enders, W. (2015). A Comparison of the information in the LIBOR and CMT term structures of interest rates. Journal of Banking \& Finance, forthcoming. http://dx.doi.org/10.1016/j.jbankfin.2015.01.

Chen, C. Y. H., Kuo, I. D., \& Chiang, T. C. (2014). What explains deviations in the unbiased expectations hypothesis? Market irrationality vs. the peso problem. Journal of International Financial Markets, Institutions \& Money, 30, 172-190. http://dx.doi.org/10.1016/j.intfin.2014.01.009006

Creal, D. D., \& Wu, J. C. (2015). Estimation of affine term structure models with spanned or unspanned stochastic volatility. Journal of Econometrics, 185, 60-81. http://dx.doi.org/10.1016/j.jeconom.2014.10.003

Cox, J. C., Ingersoll, J. E., \& Ross, S. A. (1985). A theory of the term structure of interest rates. Econometrica, 53, 385-407. http://dx.doi.org/10.2307/1911242

Diebold, F. X., \& Li, C. (2006). Forecasting the term structure of government bond yields. Journal of Econometrics, 130, 337-364. http://dx.doi.org/10.1016/j.jeconom.2005.03.005

Filipova, K., Audrino, F., \& De Giorgi, E. (2014). Monetary policy regimes: Implications for the yield curve and bond pricing. Journal of Financial Economics, 113, 427-454. http://dx.doi.org/10.1016/j.jfineco.2014.05.006

Heath, D., Jarrow, R., \& Morton, A. (1992). Bond pricing and the term structure of interest rates: A new methodology for contingent claims valuation. Econometrica, 60, 77-105. http://dx.doi.org/10.2307/2951677

Hull, J., \& White, A. (1990). Pricing interest-rate-derivative securities. Review of Financial Studies, 3, 573-592. http://dx.doi.org/10.1093/rfs/3.4.573

Johansen, S. (1991). Estimation and hypothesis testing of cointegration vectors in gaussian vector autoregressive models. Econometrica, 59, 1551-1580. http://dx.doi.org/10.2307/2938278

Johansen, S. (1995). Likelihood-based Inference in cointegrated vector autoregressive models. Oxford: Oxford University Press.

Juneja, J. (2014). Term structure estimation in the presence of autocorrelation. North American Journal of Economics and Finance, 28, 119-129. http://dx.doi.org/10.1016/j.najef.2014.02.007

Nelson, C. R., \& Seigel, A. F. (1987). Parsimonious modeling of yield curves. Journal of Business, 60, 473-489.

Shaw, F., Murphy, F., \& O'Brien, F. (2014). The forecasting efficiency of the dynamic Nelson Siegel model on credit default swaps. Research in International Business and Finance, 30, 


\section{Macrothink}

348-368. http://dx.doi.org/10.1016/j.ribaf.2012.08.007

Vasicek, O. (1977). An equilibrium characterization of the term structure. Journal of Financial Econometric, 5, 177-188. http://dx.doi.org/10.1016/0304-405X(77)90016-2

\section{Copyright Disclaimer}

Copyright for this article is retained by the author(s), with first publication rights granted to the journal.

This is an open-access article distributed under the terms and conditions of the Creative Commons Attribution license (http://creativecommons.org/licenses/by/3.0/). 